\title{
Prevalence of Sexually Transmitted Infections among cervical cancer suspected women at University of Gondar Comprehensive Specialized Hospital, North-west Ethiopia
}

Milkias Abebe ( $\nabla$ mickyelfe21@gmail.com )

Wollega University

\section{Setegn Eshetie}

University of Gondar

Belay Tessema

University of Gondar

\section{Research Article}

Keywords: HIV, HBV, HCV, syphilis, cervical cancer, Ethiopia

Posted Date: January 4th, 2021

DOl: https://doi.org/10.21203/rs.3.rs-132667/v1

License: (c) (1) This work is licensed under a Creative Commons Attribution 4.0 International License. Read Full License

Version of Record: A version of this preprint was published at BMC Infectious Diseases on April 23rd, 2021. See the published version at https://doi.org/10.1186/s12879-021-06074-y. 
1 Prevalence of Sexually Transmitted Infections among cervical cancer suspected women

2 at University of Gondar Comprehensive Specialized Hospital, North-west Ethiopia

$3 \quad$ Milkias Abebe ${ }^{1 *}$, Setegn Eshetie ${ }^{2}$, Belay Tessema ${ }^{2}$

4

$5 \quad{ }^{1}$ Department of Medical Laboratory Sciences, Institute of Health Sciences, Wollega

6 University, P.O. Box: 395, Nekemte, Ethiopia.

$7 \quad{ }^{2}$ Department of Medical Microbiology, School of Biomedical and Laboratory Sciences,

8 College of Medicine and Health Sciences, University of Gondar, P.O. Box: 196, Gondar,

9 Ethiopia.

$10 *$ Corresponding author

11 Email addresses:

12 MA: mickyelfe21@gmail.com

13 SE: wolet03.2004@ gmail.com

14 BT: $\underline{\text { bt1488@yahoo.com }}$ 


\section{Abstract}

18 Backgroud: Sexually transmitted infections (STIs) such as Human Immunodeficiency Virus

19 (HIV), Hepatitis B Virus (HBV), Hepatitis C Virus (HCV), and Syphilis have continued a

20 significant public health problem, especially in areas with substandard infection prevention

21 and control programs. It is known that STIs are largely associated with the increased

22 occurrence of cervical cancer. To date, little is known about the burden of STIs among

23 cervical cancer suspected women in Ethiopia.

24 Objectives: To assess the seroprevalence of STIs and associated risk factors among cervical 25 cancer suspected women with special emphasis on HIV, HBV, HCV, and Syphilis.

26 Methods: A hospital-based cross-sectional study was conducted among cervical cancer

27 suspected women at the University of Gondar Comprehensive Specialized Hospital from

28 February to April 2017. A pre-tested and structured questionnaire was used to collect data on

29 patients' characteristics. The patient's serum or plasma samples were tested for HIV, HBV,

$30 \mathrm{HCV}$, and syphilis using enzyme-linked immunosorbent assay. In all aspects, the standard

31 operational procedure was strictly followed. Data were analyzed using SPSS version 20

32 software and presented using tables. Statistical associations were measured using bivariate

33 and multivariable logistic regression. A p-value of below 0.05 was considered statistically 34 significant.

35 Result: A total of 403 cervical cancer suspected women with the mean age of $42.54\left(\mathrm{SD}_{\underline{1}} 11\right.$.

36 24) years were enrolled in the study. The overall prevalence of STIs was $16.6 \%(67 / 403)$ and

37 the prevalence of HIV, HBV, HCV, and syphilis was 36/403 (8.9\%), 10/403 (2.5\%), 4/403

38 (1 \%), and 29/403 (7.2\%) respectively. History of multiple sexual partners (Adjusted 
$39 \mathrm{OR}=3.02,95 \% \mathrm{CI}$ 1.57-5.79, $\mathrm{P}=0.001$ ), alcohol addiction (Adjusted OR=2.2, 95\%CI 1.07-

$404.5, \mathrm{P}=0.031$ ), history of STI (Adjusted $\mathrm{OR}=3.38 ; 95 \% \mathrm{CI}: 1.76-6.47, \mathrm{P}=0.00$ ) and not use

41 of condom (Adjusted $\mathrm{OR}=4.99 ; 95 \% \mathrm{CI}: 1.5-16.16, \mathrm{P}=0.007$ ) were significantly associated

42 with STIs.

43 Conclusion: The prevalence of STIs was generally higher among cervical cancer suspected

44 patients. Health education is encouraged to promote awareness about the prevention of STIs.

45 Key words: HIV, HBV, HCV, syphilis, cervical cancer, Ethiopia

\section{Introduction}

47 Sexually transmitted infections (STIs) are infections caused by pathogens that are mainly

48 transmitted through unsafe sexual activity. They can also spread by non-sexual contact with

49 contaminated blood, tissues, through breastfeeding, and during childbirth. Different types of

50 bacteria, viruses, and parasites can able to cause STIs (1). Viral STIs like human

51 immunodeficiency virus (HIV), human papillomavirus (HPV), hepatitis B virus, and herpes

52 simplex virus are preventable, but not treatable (2). At present, such STIs (HIV, HBV, HCV,

53 and syphilis) has continued to be a community health problem in high, middle and low

54 countries that causes acute illness, infertility, long-term disability, and death, with severe

55 medical, and psychological consequences for millions of women and infants (1). Diferrent

56 reports showed that the prevalence of STIs related with early age of initiation of sexual

57 activity, drug use before sex, and multiple sexual partners (3).

58 Thought, HPV is a necessary principal cause of cervical cancer, but it is not a sufficient cause

59 (4). Tobacco smoking, high parity, long-term contraceptive use, and co-infection with HIV

60 and other STIs (syphilis, $\mathrm{HBV}$, and $\mathrm{HCV}$ ), have been identified as established cofactors 
61 necessary for progression from cervical HPV infection to cancer (5). Women infected with

62 HIV have been shown to have a 2 to 12 fold risk of developing cervical cancer (6). This

63 relationship between HIV infection and HPV infection is also due to the fact that both are

64 sexually transmitted diseases and behaviors that put women at risk for one also put them at

65 risk for the other (6). Co-infection with other sexually transmitted diseases (syphilis, hepatitis

66 B virus, and hepatitis $\mathrm{C}$ virus) and vaginal infections are associated with increased

67 susceptibility to HPV infection (7).

68 Sexually transmitted diseases, especially HIV, HBV, HCV, and Syphilis infections are the

69 main contributing factors for cervical cancer, which is the second leading cause of cancer

70 death in women (5-7). Hence, the result of the study is helpful to design a strategy for the

71 prevention of sexually transmitted infection in cervical cancer suspected women, draw the

72 attention of stakeholders to focus on such life-threatening but preventable infections, it also

73 serves as a baseline data for the researchers who are interested in related topics. Therefore,

74 the aim of the study is to determine the prevalence of sexually transmitted infection and its

75 associated risk factors among women suspected of cervical cancer attending at University of

76 Gondar Comprehensive Specialized Hospital, North-west Ethiopia.

\section{Methods}

\section{Study design, area, and population}

79 A hospital-based cross-sectional study was conducted among women suspected of cervical

80 cancer from February to April 2017 at the University of Gondar Comprehensive Specialized

81 Hospital. University of Gondar Comprehensive Specialized Hospital is one of the largest

82 comprehensive, specialized hospitals served as a teaching as well as patient care in the 
83 Amhara region. It is located in Gondar town, $750 \mathrm{~km}$ far from Addis Ababa in Northwest

84 Ethiopia. The hospital has an accredited laboratory, more than 1200 beds, and provides

85 health care referral services for more than 5 million people from the surrounding zones and 86 nearby regions (8).

\section{Inclusion and exclusion criteria}

88 Cervical cancer suspected women (women screened for cervical cancer who had abnormal 89 vaginal bleeding such as inter-menstrual bleeding, post-coital bleeding) who are attending at

90 University of Gondar Comprehensive Specialized Hospital during the study period were

91 included in the study while patients with known STIs were excluded from the present study.

\section{Sample size and sampling procedure}

93 The sample size was calculated based on the assumption of $5 \%$ expected margins of error 94 and a $95 \%$ confidence interval, taking the prevalence of $50 \%$ by using a single population 95 proportion formula as follows.

$$
\mathrm{N}=\underline{(\mathrm{Z} \alpha / 2)^{2} \mathrm{P}(1-\mathrm{P})}
$$

98 Where $\mathrm{N}$ is the calculated sample size of cervical cancer suspected women; $\mathrm{Z}$ is the standard 99 normal deviate at $95 \%$, confidence interval $=1.96 ; \mathrm{P}$ is the prevalence of STI to get 100 maximum sample size $=50 \% ; \mathrm{d}$ is the precision level $=0.05$. Then $5 \%$ contingency $=19$ were 101 added. Finally, the total sample size $=384+19=403$ study participants.

102 The study participants were enrolled consecutively using a convenience sampling technique 103 until a sample size of 403 study participants was achieved. The detailed information of socio- 
104 demographic characteristics, behavioral characteristics, clinical and environmental

105 characteristics were collected prior to laboratory diagnosis from each of the study

106 participants using structured and pre-tested questionnaires.

\section{Laboratory diagnosis}

108 Study participants sera was tested for the presence of sexually transmitted infection (HBV, 109 HIV, HCV and syphilis) by using the Enzyme-Linked Immunosorbent Assay (ELISA). For 110 HIV1/2: Vironostika ELISA (Bio-Merieux, Boxtel, Netherlands); Furthermore, for HBsAg: 111 using ELISA, Hepanostika HBsAg (Bio-Merieux, Boxtel, Netherlands); Moreover, for HCV: 112 Human anti-HCV ELISA (Human Gesellschaft for Bio-chemical and diagnostic MbH, 113 Germany). Besides, anti-syphilis $\mathrm{Ab}$ of syphilis was checked by using DIALAB ELISA 114 (Nora Kampitsch, MSc, India).

\section{Data analysis and interpretation}

116 Data was collected, summarized, tabulated, and analyzed using Statistical Package Epi-Info 117 Version7 and Statical package for social science version 20 Software. The results were 118 presented through graphs and tables. The statistical significance, the association was 119 measured by using bivariate and multivariate analysis, odds ratio at $95 \%$ confidence 120 intervals. A p-value $<0.05$ was considered as statistically significant.

\section{Results}

\section{Socio-Demographic Data}

123 A total of 403 cervical cancer suspected women were included in the study. The majority of 124 the respondents were in the age groups of 36-49 years, 179 (44.4\%), and the mean age of 
125 study subjects was $42.54 \pm 11.24$ years. Nearly $70 \%$ of the participants were married, and 126 most of the $230(57.1 \%)$ the participants were unable to read and write and $199(49.4 \%)$ of 127 were housewives, $252(67.5 \%)$ of participants were from the urban (Table1).

\section{Prevalence of Sexually Transmitted Infection}

129 Among 403 cervical cancer suspected women $36(8.9 \%, 95 \% \mathrm{CI}=6.2-11.9)$ were $\mathrm{HIV}$ 130 positive, $10(2.5 \%, 95 \% \mathrm{CI}=1-4.2)$ were $\mathrm{HBV}$ positive, $4(1 \%, 95 \% \mathrm{CI}=0.2-2.2)$ were $\mathrm{HCV}$ 131 positive, and $29(7.2 \%, 95 \% \mathrm{CI}=4.7-9.7)$ of were syphilis positive.

133 Of the study participants, 67 (16.6\%) (95\% CI, 12.9-20.6) were found to be positive for STIs.

134 Positive STIs defined as a positive status either for single or combination of infections

135 specific to HIV, HBV, HCV, and syphilis. Of these STIs positive women, 12/67 (17.9\%) had

136 serological evidence of multiple infections. Among those with multiple infections, 9/67

137 (13.4\%) were HIV-syphilis positive, 1/67 (1.5\%) were HBV-syphilis positive, 1 (1.5\%) were 138 HCV-HIV positive and 1 (1.5\%) were HCV-syphilis positive. 


\section{Risk Factors for the acquisition of Sexually Transmitted Infections}

140 Firstly, bivariate logistic regression analysis was done and variables with $\mathrm{P}$-value $\leq 0.2$ were

141 further tested by multivariable logistic regression analysis. History the multiple sexual partners,

142 history of an STI, not using condoms, alcohol addiction were an independent risk factors for STI.

143 Patients who had multiple sexual partners were three times more likely to develop STI compared

144 to those who had no multiple sexual partner (Adjusted OR=3.02, 95\% CI 1.57-5.79, $\mathrm{P}=0.001$ ).

145 Similarly, the odds of developing STI were 3.4 times higher among patients who had a history of

146 STI compared to the counterparts (Adjusted $\mathrm{OR}=3.38 ; 95 \% \mathrm{CI}: 1.76-6.47, \mathrm{P}=0.00$ ). Besides

147 patients, who had a habit of drinking alcohol were 2.2 times more likely to have STI compared to

148 those who were not (Adjusted $\mathrm{OR}=2.2,95 \%$ CI 1.07-4.5, $\mathrm{P}=0.031$ ) (Table 2).

\section{Discussion}

150 The burden of sexually transmitted infections is high among cervical cancer suspected women 151 this is due to the fact that HPV is a sexually transmitted infection and they share a common route 152 of transmission and risk factors. This study has sought the seroprevalence of STI, HIV, HBV, $153 \mathrm{HCV}$, and syphilis infections and contributing factors for STI among cervical cancer suspected 154 women attending at the University of Gondar Comprehensive Specialized Hospital.

155 The overall prevalence of STIs in the current study was $16.6 \%(95 \% \mathrm{CI}=12.9$ to $20.6 \%)$. The 156 finding of this study was higher than studies conducted in Gondar which was 10.5\% (9) and $157 \quad 11.7 \%$ in India (10). The high prevalence of STIs among cervical cancer suspected women is due 158 to the fact that cervical cancer-causing virus and sexually transmitted infections share a common 159 route of transmission and risk factors. 
160 The present study shows that the prevalence of HIV was $8.9 \%$ (95\% $\mathrm{CI}=6.2$ to $11.9 \%$ ). It was

161 higher compared to the study conducted in Cameroon which was $4.2 \%$ (11) and $4.1 \%$ in Nigeria

162 (12). The variation could be due to the fact that cervical cancer suspected women are more risk 163 group for STIs namely HIV. An individual infected with one STIs become a high risk to be 164 infected by HIV. Human Papilloma Virus causes inflammation around the genital area which 165 increases the concentration of "activated" immune cells. Although the inflammatory response is 166 meant to help fight the HPV, HIV likes to infect some of these recruited immune cells, also 167 known as CD4 cells. Therefore, if someone has an STI (HPV) in the genitals and that area is 168 exposed to HIV, the higher concentration of "activated" CD4 cells facilitates HIV infection, 169 replication, and spread throughout the body (13). In contrast to this; higher prevalence observed 170 in South Africa, 14\% (14). This may be due to differences in socio-cultural behavior.

171

172 The seroprevalence of HBV was also noted in the current study and it was $2.5 \%$ (95\% CI=1.0 to $1734.2 \%)$. Comparable results were also reported in Ethiopia ranged from 3\% - 3.8\% (15-17). 174 However, the higher prevalence was reported in Gondar (4.7\%), Dessie (4.9\%), and Congo $175(5.9 \%)(18-20)$. This difference might be attributable to differences in risk for HBV acquisition 176 and the impact of education level. In contrast to this, the lower prevalence was reported in India $177(0.9 \%)(21)$ and Iran $(0.7 \%)(22)$. The discrepancies might be a result of differences in sampling 178 population, methodological difference, and geographical variation.

180 The prevalence of $\mathrm{HCV}$ in this study was also determined and it was $1 \%(95 \% \mathrm{CI}=0.2$ to $2.2 \%)$.

181 The finding of this study was in line with studies conducted in the Gondar Health Center $1.3 \%$ 182 (9), 0.26\% North-west Ethiopia (23). However; a higher prevalence of HCV was documented 
183 among the attendants of voluntary counseling and testing for HIV in Ethiopia 9.1\%, 6.0\%, and 4.3\% in Hawassa, Mekelle, and Adwa, respectively (24-26). The variation is due to differences in risk behavior, sampling size, and study population. Besides, HCV infection is majorly 186 acquired via blood transfusion other than other STIs.

Moreover, the prevalence of syphilis among cervical cancer suspected women in this study was 7.2\% (95\% CI, 4.7-9.7). The results from this study were in agreement with the report in South Africa 5\% (14), 6.4\% in North Tanzania (27), 5\% in Nigeria (12). Studies with lower prevalence 191 compared to our findings include; $2.3 \%$ in Gondar Health Center (9) and 2.9\% in Addis Ababa 192 (28). The high prevalence of syphilis among cervical cancer suspected women is due to the fact 193 that cervical cancer-causing virus and T. palladium have a common route of transmission and 194 risk factors. On the other hand; an extremely higher prevalence (17.4\%) was reported in 195 Cameroon (29) and 10\% in South Western Nigeria (30). The variations could be largely due to 196 geo-cultural differences and the decrease time trend of syphilis is also claimed in Ethiopia.

197 Lastly, the present study was also aimed to identify independent risk factors of STIs. The 198 distribution of STIs was significantly higher among alcohol user women than their counterparts 199 in the current study. In brief, patients, who had habit of drinking alcohol, were 2.2 times more 200 likely to have STI compared to those who were not. This might be due to the fact that alcohol use 201 is one of the common factors that lead people to exhibit risky sexual behavior and lowers a 202 person's inhibitions, which may influence their sexual behavior, and thus a compromise safe sex 203 practices (sex without condom) (31-33).

204 Additionally, the prevalence of STI was significantly higher among women who had a history of 205 STIs $(\mathrm{P}<0.001)$ which conforms to previous studies conducted in Jimma (15) and Peru (34). 
206 Moreover, the prevalence of STI was also significant and three times higher among the study

207 subjects who had a history of multiple sexual partners compared to their counterparts. This is due

208 to women who have multiple sexual partners who had a chance of getting sex with an infected

209 person.

210 Furthermore, STI prevalence was five times higher among study participants who have not used

211 condoms compared to their counterparts. Without any doubt, the condom is one of the preventive

212 strategies against STIs. Evidently, consistent and correct use of condoms is $90 \%$ effective in

213 reducing HIV, up to 66\% effective in reducing syphilis (35). Similarly, studies have done in New

214 York and Southwestern China support the advantage of condoms in preventing STI (36,37). In

215 this study, however, STI did not show any correlation with the history of blood transfusion, 216 tattooing, surgical operation, smoking, and genital mutilation in the present study. This is similar 217 to previous studies in Ethiopia $(16,38)$.

\section{Conclusion}

219 This study shows the prevalence of sexually transmitted infections was generally higher among 220 cervical cancer suspected women. Having multiple sexual partners, not using condoms, alcohol 221 addiction, and history of STIs found to be independent risk factors for sexually transmitted 222 infections.

223 Since STIs are major health problems in cervical cancer suspected women, all cervical cancer 224 suspected women should be screened for STIs (syphilis, HBV, HCV), increase awareness of 225 people on modes of transmission of sexually transmitted infections and educate people how to 226 prevent sexually transmitted infections could help in reducing the burden of STIs. 


\section{Declarations}

\section{Acknowledgments}

229 We would like to thank all study participants.

\section{Authors' contributions}

231 MA was conceived the study, designed data collection, conducted data analysis and

232 interpretation. BT and SE interpreted the results and reviewed the initial and final drafts of the

233 manuscript. All authors read and approved the final manuscript.

\section{Funding}

235 Not applicable.

\section{Availability of data and materials}

237 All data generated or analyzed during this study were included in this article.

\section{Ethics approval and consent to participate}

239 This research was conducted after obtaining ethical clearance from School of Biomedical and

240 Laboratory Sciences of the University of Gondar ethical review committee with reference

241 number SBMLS/625/08. Written informed consent was obtained from Study participants after

242 explaining the purpose and objective of the study. Any patient who was not willing to participate

243 in the study wasn't forced to participate. All data and samples obtained from them were kept

244 confidential by using codes instead of any personal identifiers and were meant only for the

245 purpose of the study. The laboratory results of the study participant were communicated to their

246 physicians for medical care. All methods were performed in accordance with the relevant guidelines 247 and regulations in the Declaration of Helsinki. 


\section{Consent for publication}

249 Not applicable.

\section{Competing interests}

251 The authors declare that they have no competing interests.

\section{Author details}

$253{ }^{1}$ Department of Medical Laboratory Sciences, Institute of Health Sciences, Wollega University, P.O. Box:

254 395, Nekemte, Ethiopia.

$255 \quad{ }^{2}$ Department of Medical Microbiology, School of Biomedical and Laboratory Sciences, College of 256 Medicine and Health Sciences, University of Gondar, P.O. Box: 196, Gondar, Ethiopia.

\section{References}

258 1. Geremew RA, Agizie BM, Bashaw AA, Seid ME, Yeshanew AG. Prevalence of Selected Sexually

259 Transmitted Infection (STI) and Associated Factors among Symptomatic Patients Attending

260 Gondar Town Hospitals and Health Centers. Ethiop J Health Sci. 2017;27(6):589-600.

2612 2. De Schryver A, Meheus A. Epidemiology of sexually transmitted diseases: The global picture.

262 Bull World Health Organ. 1990;68(5):639-54.

263 3. Diclemente R, Wingood G, Sionean C, Crosby R, Harrington K, Davies S, et al. Association of 264 Adolescents' History of Sexually Transmitted Disease ( STD ) and Their Current High-Risk 265 Behavior and STD Status. Sex Transm Dis. 2002;29(9):503-9.

266 4. Carlson LM, Gonzalez S. Knowledge of cervical cancer pathology of high school students in San Carlos, Costa Rica. Rev Biol Trop. 2014;62(3):877-86.

5. Smith JS, Herrero R, Bosetti C, Muñoz N, Bosch FX, Eluf-Neto J, et al. Herpes simplex virus-2 as a human papillomavirus cofactor in the etiology of invasive cervical cancer. J Natl Cancer Inst. 
271 6. Mapanga W, Girdler-Brown B, Feresu SA, Chipato T, Singh E. Prevention of cervical cancer in 272 HIV-seropositive women from developing countries through cervical cancer screening: A $273 \quad$ systematic review. Syst Rev. 2018;7(1):198.

274 7. King CC, Jamieson DJ, Wiener J, Cu-Uvin S, Klein RS, Rompalo AM, et al. Bacterial vaginosis 275 and the natural history of human papillomavirus. Infect Dis Obstet Gynecol. 2011;2011:1-8.

276 8. Molla R, Tiruneh M, Abebe W, Moges F. Bacterial profile and antimicrobial susceptibility patterns in chronic suppurative otitis media at the University of Gondar Comprehensive Specialized Hospital, Northwest Ethiopia. BMC Res Notes [Internet]. 2019;12(1):1-6. Available from: https://doi.org/10.1186/s13104-019-4452-4

9. Tiruneh M. Seroprevalence of multiple sexually transmitted infections among antenatal clinic attendees in Gondar Health Center , northwest Ethiopia. Ethiop Med J. 2008;46(4):359-66.

10. Hussain T, Kulshreshtha KK, Sinha S, Yadav VS, Katoch VM. HIV , HBV , HCV , and syphilis co-infections among patients attending the STD clinics of district hospitals in Northern India. Int J Infect Dis. 2006;10:358-63.

11. Goh BT. Syphilis in adults. sex Transm Infect. 2005;448-52.

12. Buseri F, Jeremiah Z, Seiyaboh E. Surveying infections among pregnant women in the Niger Delta, Nigeria. J Glob Infect Dis. 2010;2(3):203-11.

13. Quinn TC, Wawer MJ, Sewankambo N, Serwadda D, Li C, Wabwire-Mangen F, et al. Viral load and heterosexual transmission of human immunodeficiency virus type 1. N Engl J Med. 2000;342(13):921-9. 
Transmission of HIV and Syphilis Testing and Treatment in Antenatal Care Services in the Northern Cape and Gauteng Provinces, South Africa. Sex Transm Dis. 2013;40(11):846-51.

294 15. Awole M, Gebre-Selassie S. Seroprevalence of HBsAg and its risk factors amoung pregnant women in Jimma, Southwest Ethiopia. Ethiop J Heal Dev. 2005;19(1):45-50.

16. Zenebe Y, Mulu W, Yimer M, Abera B. Sero-prevalence and risk factors of hepatitis B virus and human immunodeficiency virus infection among pregnant women in Bahir Dar city, Northwest Ethiopia : a cross sectional study. BMC Infect Dis. 2014;14(1):1-7.

17. Tegegne D, Desta K, Tegbaru B, Tilahun T. Seroprevalence and transmission of Hepatitis B virus among delivering women and their new born in selected health facilities, Addis Ababa, Ethiopia : a cross sectional study. BMC Res Notes. 2014;7(1):1-7.

18. Tessema B, Yismaw G, Kassu A, Amsalu A, Mulu A, Emmrich F, et al. Seroprevalence of HIV , HBV , HCV and syphilis infections among blood donors at Gondar University Teaching Hospital , Northwest Ethiopia : declining trends over a period of five years. BMC Infect Dis. 2010;10:111.

19. Seid M, Gelaw B, Assefa A. Sero-prevalence of HBV and HCV Infections Among Pregnant Women Attending Antenatal Care Clinic at Dessie Referral Hospital , Ethiopia. Adv Life Sci Heal. 2014;1(2):109-20.

20. Kabinda JM, Akilimali TS, Miyanga AS, Donnen P, Michèle D. Hepatitis B , Hepatitis C and HIV 309 in Pregnant Women in the Community in the Democratic Republic of Congo. World J AIDS.

21. Dwivedi M, Misra SP, Misra V, Pandey A, Pant S, Singh R, et al. Seroprevalence of hepatitis B infection during pregnancy and risk of perinatal transmission. Indian J Gastroenterol. 2011;30(2):66-71. 
314 22. Mohebbi SR, Sanati A, Cheraghipour K, Nejad MR, Shalmani HM, Zali MR. Hepatitis C and hepatitis B virus infection: Epidemiology and risk factors in a large cohort of pregnant women in Lorestan, West of Iran. Hepat Mon. 2011;11(9):736-9.

317 23. Molla S, Munshea A, Nibret E. Seroprevalence of hepatitis B surface antigen and anti HCV 318 antibody and its associated risk factors among pregnant women attending maternity ward of 319 Felege Hiwot Referral Hospital, northwest Ethiopia : a cross-sectional study. Virol J. 2015;12:204.

24. Alemayehu A, Tassachew Y, Sisay Z, Shimelis T. Prevalence and risk factors of Hepatitis C among individuals presenting to HIV testing centers, Hawassa city, Southern Ethiopia. BMC Res Notes. 2011;4:193.

25. Hadush H, Gebre-Selassie S, Mihiret A. Hepatitis C virus and Human Immunodeficiency Virus coinfection among attendants of Voluntary Counseling and Testing Centre and HIV follow up clinics in Mekelle Hospital. Pan Afr Med J. 2013;14:107.

26. Atsbaha AH, Dejen TA, Belodu R, Getachew K, Saravanan M, Wasihun AG. Sero - prevalence and associated risk factors for hepatitis $\mathrm{C}$ virus infection among voluntary counseling testing and anti retroviral treatment clinic attendants in Adwa hospital, Northern Ethiopia. BMC Res Notes. 2016;9:121.

27. Kumogola Y, Slaymaker E, Zaba B, Mngara J, Isingo R, Changalucha J, et al. Trends in HIV \& syphilis prevalence and correlates of HIV infection : results from cross-sectional surveys among women attending ante-natal clinics in Northern Tanzania. BMC Res Notes. 2010;10:553.

334 28. Kebede E. and Chamiso. Prevalence of syphilis in pregnancy in Addis Ababa. East Afr Med J. 2000;77(4):212-6. 
30. Ojo DA, Oyetunji IAO. Sero-prevalence of syphilis among pregnant women in Osogbo in Southwestern Nigeria. ASSET Ser B. 2007;6(1):61-5.

31. Regassa N, Kedir S. Attitudes and practices on HIV preventions among students of higher education institutions in Ethiopia : the case of Addis Ababa University. East Afr J Public Heal. 2011;8(2):141-54.

32. Malaju MT, Asale GA. Association of Khat and alcohol use with HIV infection and age at first sexual initiation among youths visiting HIV testing and counseling centers in Gamo-Gofa Zone, South West Ethiopia. BMC Int Health Hum Rights. 2013;13:10.

33. Gelibo T, Belachew T, Tilahun T. Predictors of sexual abstinence among Wolaita Sodo University Students, South Ethiopia. Reprod Health. 2013;10:18.

34. Alarcon JO, Johnson KM, Courtois B, Rodriguez C, Sanchez J, Watts DM, et al. Determinants and prevalence of HIV infection in pregnant Peruvian women. AIDS. 2003;17(4):613-8.

35. Hocking J FC. Associations between condom use and rectal or urethral chlamydia infection in men. Sex Transm Dis. 2006;33(4):256-8.

36. Caico C. Sexually Risky Behavior in College-Aged Students. Open J Prev Med. 2014;4:354-64.

353 37. Hu Y, Liang S, Zhu J, Qin G, Liu Q, Song B, et al. Factors Associated with Recent Risky Drug Use and Sexual Behaviors among Drug Users in Southwestern China AIDS \& Clinical Research. J AIDS Clin Res. 2011;2(3):1-6.

38. Abera B, Zenebe Y, Mulu W, Kibret M, Kahsu G. Seroprevalence of hepatitis B and C viruses and risk factors in HIV infected children at the felgehiwot referral hospital, Ethiopia. BMC Res Notes. 2014;7:838. 
360 Table 1: - Socio-demographic characterstics of cervical cancer suspected women at University 361 of Gondar Comprehensive Specialized Hospital.

\begin{tabular}{|c|c|c|}
\hline Characteristics & Frequency & Percent \\
\hline \multicolumn{3}{|l|}{ Age } \\
\hline$<=35$ years & 123 & 30.5 \\
\hline 36- 49years & 179 & 44.4 \\
\hline$<=50$ years & 101 & 25.1 \\
\hline Total & 403 & 100 \\
\hline \multicolumn{3}{|l|}{ Marital status } \\
\hline Married & 280 & 69.5 \\
\hline Divorce & 63 & 15.6 \\
\hline Widowed & 60 & 14.9 \\
\hline Total & 403 & 100 \\
\hline \multicolumn{3}{|l|}{ Educational level } \\
\hline Unable to read and write & 230 & 57.1 \\
\hline Primary & 71 & 17.6 \\
\hline Secondary & 52 & 12.9 \\
\hline Diploma & 39 & 9.7 \\
\hline Degree and above & 11 & 2.7 \\
\hline Total & 403 & 100 \\
\hline
\end{tabular}

\section{Occupational status}


Self employed

House Wife

Merchant

Government employed

Farmer

Total

Residence

Rural

Urban

Total
15

199

47

46

96

403

151

252

403
3.7

49.4

11.7

11.4

23.8

100

37.5

62.5

100

362

Table 2: - Risk factors of STIs among cervical cancer suspected at University of Gondar

363 Comprehensive Specialized Hospital.

Variables

STIs status

COR $(95 \% \mathrm{CI})$

P-vale

AOR (95\% CI)

P-value

$\operatorname{Neg}(\mathrm{N}) \quad$ Pos $(\mathrm{N})$

Multiple sexual partner

No

197

20

1

Yes

139

47

$3.33(1.89-5.87)$

0.00

$3.02(1.57-5.79)$

$0.001 *$

\section{Tattooing}

$\begin{array}{lrrllll}\text { No } & 126 & 18 & 1 & & & \\ \text { Yes } & 210 & 49 & 1.63(0.91-2.93) & 0.099 & 1.05(0.54-2.03) & 0.9\end{array}$

\section{History of Abortion}

$\begin{array}{llll}\text { No } & 244 & 39 & 1\end{array}$

Yes

92

28

1.9(1.11-3.27)

$0.020 \quad 1.5(0.79-2.85)$

0.217 


\section{Tooth extraction}

No

Yes

\section{History of STI}

No

Yes

\section{Using Condom}

Yes

No

Alcohol addiction

No

Yes

Smoke Cigarette

No

Yes
223

113

264

72

61

275

148

188

14

53

63

3.5(1.23-9.96)

$0.019 \quad 4.99(1.5-16.16)$

$0.007 *$

0.33 